\title{
Reconstruction of a hotel complex building part, taking into account the volumetric planning solution changes
}

\author{
Galina Voronkova, Sergey Rekunov*, and Alexey Churakov \\ Volgograd State Technical University, 400005, Volgograd, Russia
}

\begin{abstract}
The paper presents the hotel complex building reconstruction main stages. The self-supporting wall stress-strain state analysis is carried out, taking into account the organization of additional doorways in it. The optimal parameters of their location are given taking into account the arising stress concentrators. The procedure for performing the production of works is given.
\end{abstract}

\section{Introduction}

To increase the hotel complex attractiveness in the city of Volgograd, a long-term development plan has been developed. One of the points of this plan was to reconstruct the two-story part of the restaurant. It has been proposed to build it up to the common cornice and add an attic floor. The architectural solution included the installation of additional doorways in the basement and a large opening on the first floor of the restaurant.

\section{Technical inspection}

A preliminary assessment of the structures' technical condition was made in connection with the need to change the technological regulations, which entailed a change in the spaceplanning solution of a part of the building [1,2].

Inspection of the above-ground part of the building showed that there were cracks on the courtyard facade in the upper part, developing from the supporting part of the arched vaults of the windows to the top of the building. At the cornice level, the crack opening width was $5 \div 10 \mathrm{~mm}$. On the side facade, a number of vertical cracks and delamination of the facing tiles were revealed in the area $2 \div 3 \mathrm{~m}^{2}$. Vertical cracks reached the cornice.

When inspecting the basement, significant precipitation was found on the floor, floor slabs of the first floor and partitions. The difference in the ceiling level marks along the partition at a distance of $3 \mathrm{~m}$ was $150 \mathrm{~mm}$. The brick wall, in which the openings were supposed to be made, had numerous stepped displacements along the seams. The paper strip beacons installed to control the deformation process were torn apart. The floors in the described area had dips in $200 \div 250 \mathrm{~mm}$.

\footnotetext{
* Corresponding author: rekunoff@mail.ru
} 
Previously, to maintain the floor slab in working order, it was reinforced with a metal frame.

Before proceeding with the reconstruction, it was necessary to identify the causes of these deformations. [3].

A detailed study of the basements and foundations state was carried out for this. On the basis of this study, an analysis of the soils stress-strain state, analytical calculations of foundations were carried out and technical projects were developed to strengthen the columns and foundations.

At the time of this study, the construction department of the restaurant was carrying out work to strengthen the foundations in accordance with the proposed recommendations, which made it possible to start performing analytical calculations and analysis of the walls stress-strain state in a weakened state.

\section{Analysis of the walls' stress-strain state in a weakened state}

The openings were made in self-supporting walls; therefore, the own weight of the brickwork was taken as the load [4]. The analytical calculation of the lintel was carried out on the assumption that continuous vertical cracks are formed along the edges of the opening, thus, the brick wall weight is completely transferred to the lintel [5]. The position of the openings relative to the horizontal dimensions of the wall had to be determined from the stress diagrams, choosing the smallest possible values. Since the wall works in a planestressed state [6], a beam-wall was taken as the design scheme.

First, the calculation from the wall to the opening structure was performed (Fig. 1).

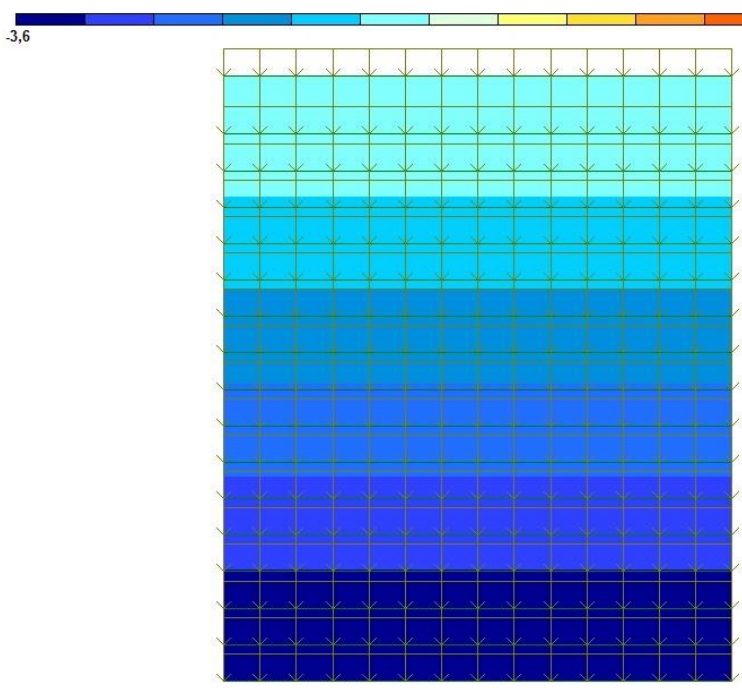

Fig. 1. Plane stress state of the wall to the opening structure

The diagram clearly shows the monotonous nature of the forces' distribution in the wall material. Maximum compressive force is $36 \mathrm{kN} / \mathrm{m}^{2}$.

In further calculations, two doorways in the basement and a symmetrically located opening on the first floor were introduced (Fig. 2). 


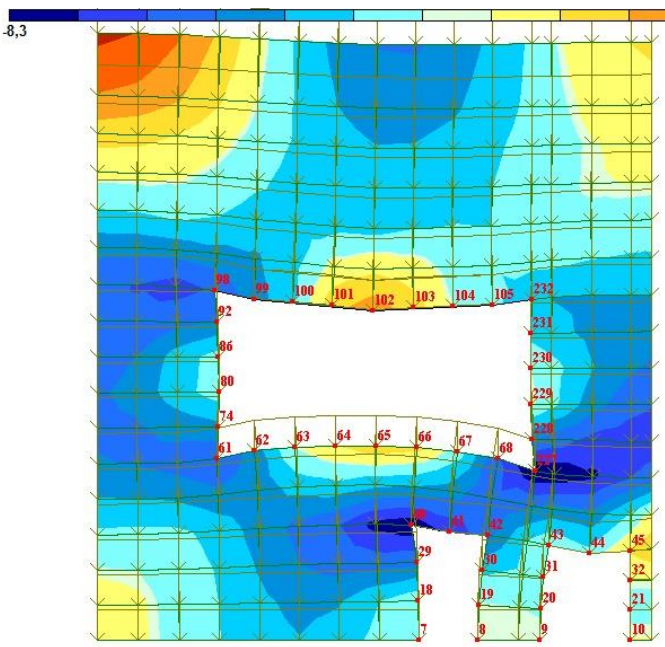

Fig. 2. Plane stress state of the wall. The opening on the ground floor is located symmetrically

The force diagram clearly shows that the symmetrical arrangement of the 4-meter-long opening leads to a significant concentration of stresses in the wall. Maximum compressive force $83 \mathrm{kN} / \mathrm{m}^{2}$. Also, the opening structure leads to an uneven distribution of stresses, tensile forces appear in the upper part of the wall.

When constructing this opening, it is advisable to displace it, as shown in Fig. 3. Maximum compressive force $66 \mathrm{kN} / \mathrm{m}^{2}$.

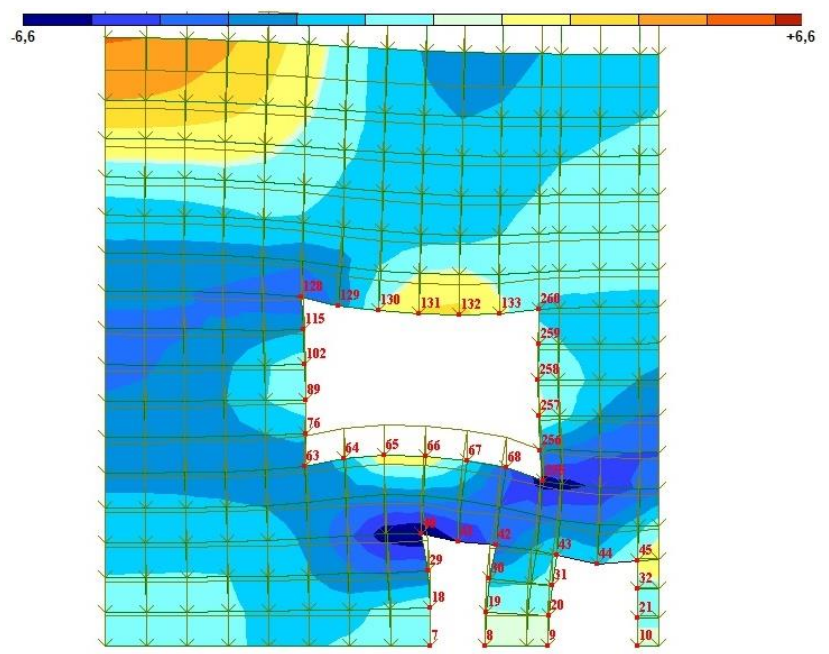

Fig. 3. Plane stress state of the wall. The opening on the ground floor is shifted to the right

To prevent the cracks formation in the middle of such an opening, it is necessary to put a post [7], but this solution did not satisfy the customer. Therefore, it was proposed to reduce the opening to three meters and arrange an additional opening on the left side of the wall (Fig. 4). After the construction of such an opening, a redistribution of efforts occurred. The maximum compressive force has become $59 \mathrm{kN} / \mathrm{m}^{2}$. 


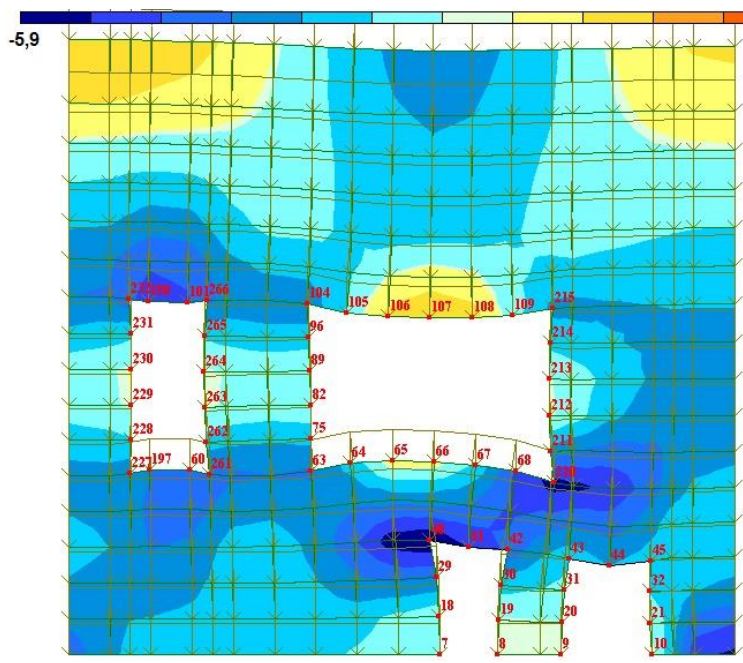

Fig. 4. Plane stress state of the wall. Arranged additional opening

Implementation of the proposed recommendations contributes to a more even distribution of internal efforts and displacements [8].

The drawings were developed for the construction of openings $[9,10]$, one of them is shown in Fig. 5.

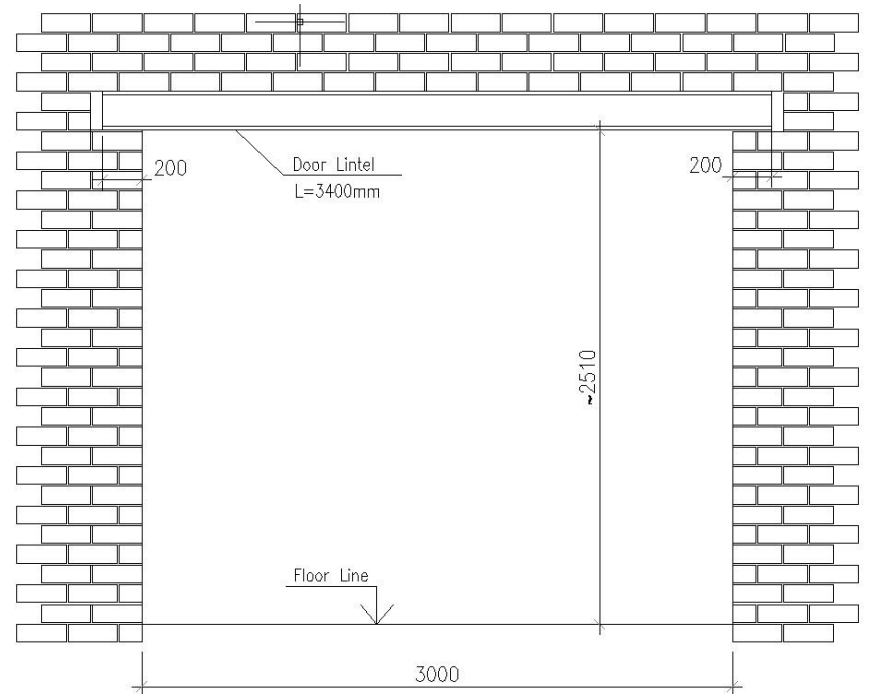

Fig. 5. Fragment of the opening structure drawing

\section{The work order}

The structure of an opening in a self-supporting wall should be performed in the following order:

1. Using a hand-held cutting power tool, cut the masonry along the horizontal seams, in the places corresponding to the marks of the bottom and top of the lintel, to a depth of 150-160 mm along the seam. The cut part length must correspond to the length of the opening plus $500 \mathrm{~mm}(250 \mathrm{~mm}$ on each side). 
2. To cut vertical slots at a distance of $250 \mathrm{~mm}$ from the edges of the projected opening with a height of $310 \mathrm{~mm}$. Vertical cuts must connect previously made horizontal cuts.

3. To make a successive excavation of the upper spoon row of bricks and free up completely the space for the lintel installation.

4. To cut the lower horizontal seam to a depth of $30 \mathrm{~mm}$ and break off the brick vertical edge bottom for the lintel smooth installation.

5. To install the lintel to the design position, sinking the outer edge of the flange into the wall body by at least $30 \mathrm{~mm}$.

6. To perform similar operations on the opposite side of the wall.

7. To cut vertical slots along the line of the opening to be arranged.

8. To excavate bricks from under the lintels with a step of $770 \mathrm{~mm}$ on both sides of the wall.

9. To drill holes in a brick wall with a diameter $16 \div 18 \mathrm{~mm}$ for installing connecting rods.

10. To weld the connecting rods along the lintels bottom.

11. To make a brick excavation along the top of the lintels with a step of $770 \mathrm{~mm}$.

12. To caulk the space between the channel and the brick with plastic cement-sand mortar [11], to seal it by lightly tapping a hammer on the channel wall.

13. To install the top brick to the design position.

14. To disassemble the brickwork under the lintel.

15. To complete finishing work.

\section{Conclusion}

Several options for the openings' arrangement in a self-supporting wall have been considered. The main difference in these options was the location of the large opening on the ground floor. The greatest values of stress concentrators arise in the variant when the opening 4 meters wide is located in the center of the wall. Also, in this version, it is necessary to put the stand in the middle of the opening to prevent cracks' formation, which did not meet the customer's requirements. Reducing the opening width and shifting it to the right led to a decrease in the stress values.

The analysis of the calculation results showed that the most expedient is the structure of an additional opening with a width of $1 \mathrm{~m}$ and an opening with a width of $3 \mathrm{~m}$. In this case, the wall between the openings should be $1.25 \mathrm{~m}$. This option was approved by the customer. The building reconstructed according to this option has been in operation for 5 years.

\section{References}

1. O.B. Zavyalova, Industrial and Civil Engineering 7, 58-61 (2012)

2. A.I. Bedov, V.F. Saprykin, Inspection and reconstruction of reinforced concrete and stone structures of operated buildings and structures (Moscow, 1995)

3. O.V. Kabantsev, A.G. Tamrazyan, Engineering and construction journal 5 (49), 15-26 (2014)

4. N.V. Kupchikova, Industrial and Civil Engineering 10, 29 (2007)

5. G.V. Voronkova, S.S. Rekunov, O.V. Dushko, IOP conference series, Materials science and engineering /iopscience.iop.org/article/10.1088/1757-899X/753/3/032088 (2020)

6. S.D. Poojara, IJCIET 5 (3), 294-300 (2014)

7. N.F. Grace, Concrete international 26 (5), 45-51 (2004) 
8. V.V. Pavlov, E.V. Khorkov, Bulletin of Civil Engineers 5 (70), 94-97 (2018)

9. A.G. Tamrazyan, M.A. Orlova, Housing construction 6, 32-34 (2015)

10. S. S. Rekunov, Transport facilities 3 (2), 7 (2016)

11. V.A. Klevtsov, D.V. Kuzevanov, Concrete and reinforced concrete 2, 9-13 (2009) 